\title{
Applying epistemology to editing
}

The definitive edition of Russell's Collected Essays should present his text just as he finally intended it to be. Knowledge of his final intentions, however, is often difficult to obtain. In very many cases there is conflicting evidence. There may be variations between one or more manuscripts, typescripts (and differing carbon copies), proofs, and different settings of type. Hunting down the variants is relatively simple. What to do about them - even after a decision among them has been made - is the difficult problem. Often we can never know who among the several persons through whom a text passcd on its way to being published was responsibie for the variations from Russell's manuscript, and whether he approved. But although indubitable knowledge mas be unobtainable, the al ternative is not guess-work. Instead, a reasoned choice maly be made alternative is hot guessume lnstead, a reasoned choice may be made, and the evidence for the choice hot suppressed but presented to the
in applied epistemology.

(continued on p. 24) 
(continued from p. 2)

Take, for example, the case of the article which is represented by a manuscript in Russell's hand and a single printed text, between which there are variations. There is not sufficient reason a priori to accept either version in toto. This is because we do not know the sources of the variations. The differences in the printed version may be due to intervention by a publisher's editor, typesetter or proofreader; or they may be due to the intervention of Russell himself at a missing typescript stage, his reading of the proofs (if he saw them), or even in a letter to the publisher. The missing link provided by the hypothetical typescript can often be the source of variations. We can see this if we examine the top copies of typescripts which were returned to Russell. When no typescript is available, it is still often likely that one did exist, for the manuscript may be clean (unlike one that's been returned from a typesetter) and never have been folded as if for mailing.

In a definitive edition it is customary to present both the "final" text and at least some of the variants as evidence of how the author's text and at least some of the variants as evidence of how the author'
intentions were determined. It might be said that it doesn't matter whether the printed or manuscript text is printed in toto since variants whether the printed or manuscript text is printed in toto since variants
are going to be given in footnotes or appendices. But this is unsatisfactory. Most users of the definitive edition will not be examining the variants - even if they are handily printed as footnotes. They will expect the main printed text to contain all the preferred readings. The editors are therefore faced with the problem of constructing an eclectic text.

I have chosen as an example of this procedure a short article published in the Hearst chain's New York American of August 3, 1934. Both the manuscript and a photocopy of the printed article are in the Brchives. Weither version secms to the printed artice are in the Archives. Nelther version seems to embody Russell's final intentions and only those lintentions. The printed version omits a sentence at 1.43 "The only way of avoiding this danger is through a defensive organization of the teachers, to protect their intellectual independence and resist all attempts at wrongful dismissal for opinions offensive to ignorance or bias." This is surely due to its political content. The manuscript, however, seems to have been improved at two points. There are several other variations, principally in paragraphing, punctuation and printing style. We think the definitive edition would be better of with a consistent style, and that style may as well be Russell's. His style in punctuation is logical, beautiful, subtle - and consistent. His prose is perfect for reading aloud, partly because of the punctuation. We are therefore not considering replacing his style by that of one of the widely-used style manuls, except in the case of italicizing titles of books and magazines, which Russell indicated by quotation marks.

The variants Iisted below the text include only the "substantive" ones. "Accidental" variants (such matters as punctuation and spelling) have been considered, but the variants are not thought to be worth recording. The "copy-text" was the manuscript. It has been emended to accomodate accepted variants from the printed text.

The alterations within the mauscript, in contrast to the way in which "[The Status of Women]" was edited in Russell 14, are not recorded. They are irrelevant to our knowledge of Russell's final intentions. Another contrast is in the way in which the variants are indicated. Here a line number has simply been provided. In editing the former essay $I$ put footnote numbers in the text. Marking up the text with variant input footnote numbers in the text. Marking up the text with variant in-
dicators does not seem justified, as it interferes with the smooth readdicators does not seem justified, as it interferes with the smooth read-
ing that the great majority of readers desire in their. Russell books. ing that the great majority of readers desire in their. Russell books.
But in order not to maximize the inconvenience to readers who use variants, it seems useful to print them, in small type, at the foot of the pages to which they belong, rather than at the back of a volume. 